\title{
Perawatan Bayi Baru Lahir dengan Pendekatan Model Mother-Baby Care $(M-B C)$ Sebagai Inovasi dalam Upaya Memandirikan Ibu Postpartum
}

\author{
a Vetty Priscilla \\ ${ }^{a}$ Fakultas Keperawatan Universitas Andalas \\ E-mail: vettypriscilla@gmail.com
}

\begin{abstract}
Newborn care is very important to do after the baby was born and is useful for both mother and baby. Rapid resumption of maternal organs that undergo changes during pregnancy is one of the advantages besides make warm relationship between mother and baby. The purpose of this study was to make postpartum mothers to be more independent in order to care of newborn by using model of Mother-Baby Care (M-BC). This study was using a qualitative design with a grounded theory approach. The sample was 10 postpartum in Dr MJamil hospital Padang. The result is an innovation model of Mother-Baby Care $(M-B C)$ in newborn care. It is recommended especially for health workers to use this model as one of the innovations in the newborn care.
\end{abstract}

Key words: Newborn, Mother-Baby Care M-BC), postpartum

\begin{abstract}
Abstrak: Perawatan bayi baru lahir sangat penting dilakukan setelah bayi lahir dan sangat bermanfaat baik untuk ibu maupun bayi seperti cepatnya pemulihan organ tubuh ibu yang mengalami perubahan pada saat kehamilan serta terbinanya hubungan kasih sayang antara ibu dan bayi. Tujuan penelitian ini untuk memandirikan ibu postpartum dalam perawatan bayi baru lahir dengan mengunakan pendekatan model MotherBaby Care (M-BC). Penelitian ini mengunakan desain penelitian kualitatif dengan pendekatan grounded theory. Sampel penelitian ini adalah ibu postpartum yang berjumlah 10 orang di RSUP Dr MJamil Padang. Hasil penelitian adanya inovasi model Mother Babyi Care (M-BC) dalam perawatan bayi baru lahir yang bertujuan untuk memandirikan ibu postpartum. Disarankan terutama kepada petugas kesehatan untuk mengunakan model ini sebagai salah satu inovasi dalam melakukan perawatan bayi baru lahir.
\end{abstract}

Kata kunci: Bayi baru lahir, Mother-Baby Care (M-BC), postpartum

\section{PENDAHULUAN}

Derajat kesehatan suatu negara bisa dilihat dari nilai indikator kesehatan di negara tersebut. Indikator kesehatan yang bisa dilihat seperti Angka Kematian Ibu (AKI) dan Angka Kematian Bayi (AKB). Manurut Survey Demografi dan Kesehatan Indonesia (SDKI) 2007 AKI di Indonesia adalah 228/100000 kelahiran hidup, sedangkan AKB adalah 34/1000 kelahiran hidup. Dibandingkan dengan SDKI sebelumnya, angka ini telah mengalami penurunan akan tetapi jika dibandingkan dengan negara-negara di Asia Tenggara, angka ini masih tergolong tinggi. Tingginya angka kematian ibu dan bayi salah satunya dipicu oleh terlambatnya pasien mencari bantuan. Seringkali pasien sudah datang ke pelayanan kesehatan dalam keadaan yang cukup parah. Sasaran pembangunan kesehatan di Indonesia yaitu menurunnya AKI sebesar 118 per 100 ribu $\mathrm{KH}$ (Kelahiran Hidup) dan menurunnya angka kematian bayi (AKB) sebesar 24 per 1000 KH dan pada tahun 2015 (Depkes, 2011).

Rumah sakit Dr. M Djamil Padang merupakan rumah sakit rujukan untuk wilayah Sumatera Barat termasuk rujukan yang terkait dengan kesehatan ibu dan anak. Rumah sakit merupakan unit pelayanan kesehatan yang mempunyai peran besar dalam memberikan konstribusi dalam usaha 
kuratif, rehabilitative, pendidikan dan penelitian. Oleh karena itu, diperlukan pengelolaan secara professional dari berbagai profesi kesehatan untuk mewujudkan hal di atas. Melakukan perbaikan dan meningkatkan kualitas pelayanan merupakan strategi yang bisa dilakukan. Tujuannya agar pasien yang datang dalam keadaan cukup parah dapat di tanggani dengan baik sehingga nyawa pasien bisa terselamatkan. Tapi yang tak kalah pentingnya adalah bagaimana perawatan pasien setelah dia melewati masa kritis seperti halnya bagaimana perawatan ibu dan bayi di Ruang Perawatan Maternitas/Kebidanan setelah ibu melahirkan.

Bayi yang lahir dipandang sebagai bagian dari keluarga. Perawatan bayi tidak terlepas dari peran serta keluarga. Perawatan bayi yang baik dan benar akan dapat mencegah bayi dari suatu keadaan yang tidak diinginkan dan bisa membuat bayi menjadi bugar dan sehat. Diharapkan bayi akan bisa tumbuh dan berkembang menjadi generasi yang cerdas. Oleh karena itu, perawatan bayi haruslah dimulai sedini mungkin dengan melibatkan keluarga terutama orang yang dekat dengan bayi seperti ibu. Pendekatan yang bisa dilakukan adalah dengan mengunakan model perawatan ibu dan bayi atau lebih dikenal dengan mother-baby care $(M-B C)$. Pengunaan pendekatan dengan model yang tepat diharapkan dapat berkonstribusi terhadap penurunan angka kematian ibu dan bayi di Indonesia khususnya di Sumatera Barat.

Mother-Baby Care (M-BC) merupakan model memandirikan pasien yang bertujuan untuk membelajarkan pasien agar kebutuhannya terpenuhi. Disamping itu, M-BC juga merupakan pendekatan yang bisa dilakukan oleh tenaga kesehatan seperti perawat untuk memberikan dukungan emosional kepada keluarga baru (Alligood \& Tomey, 2002). Konsep $M-B C$ ini didasari oleh konsep keperawatan maternitas yang berfokus pada keluarga. Hal ini didasarkan tidak hanya pada dimensi fisik saja akan tetapi juga dimensi psikologis, sosial dan ekonomi (May, K A \& Mahlmeister, L.R., 1994). Diharapkan pendekatan ini bisa digunakan oleh semua tenaga kesehatan yang bertugas di Ruang Maternitas/Kebidanan.

Dari survey awal yang dilakukan oleh peneliti di Ruang Kebidanan Lt 2 Rumah Sakit Dr M Jamil Padang, didapatkan data bahwa selama Bulan Maret 2011 terdapat 140 ibu yang melahirkan dimana 95 orang melahirkan dengan metode operasi/seksio dan 45 orang pervaginam. Sedangkan dari wawancara awal didapatkan data bahwa hampir semua ibu tidak mengetahui bagaimana cara perawatan mandiri pada bayi baru lahir walaupun ibu tersebut berstatus primipara maupun multipara. Dari 10 orang ibu yang diobservasi, sekitar $20 \%$ ibu yang terlihat mandiri merawat bayinya, sedangkan yang lainnya masih terlihat binggung bagaimana berperilaku benar terhadap perawatan bayi. Mengingat pentingnya perawatan mandiri ini maka, peneliti tertarik untuk melakukan suatu pendekatan sebagai upaya memandirikan ibu dengan harapan ibu sehat dan bayi sehat sehingga secara tidak langsung akan berdampak pada tidak terjadinya kematian ibu dan bayi.

\section{METODE}

Pendekatan yang digunakan dalam penelitian ini adalah pendekatan kualitatif. Menurut Burns \& Grove (2001), pendekatan kualitatif yaitu pendekatan yang mempunyai filosofi alamiah dan mempunyai fokus yang lebih luas untuk mengetahui pemahaman responden terhadap fenomena unik yang peneliti temukan. Metode penelitian yang digunakan adalah grounded theory dengan melihat fenomena yang ada disekumpulan orang kemudian fenomena tersebut dianalisi dan kemudian dikembangkan untuk memperbaharui model yang sudah ada. Dalam hal ini adalah model Mother-Baby Care $(M-B C)$. Penelitian ini sesuai dengan penelitian yang dilakukan oleh peneliti dimana pada saat ini peneliti ingin melihat 
dan mengetahui fenomena apa yang ada pada saat ibu postpartum melakukan perawatan pada bayi baru lahir. Fenomena akan dilihat secara obyektif. Berdasarkan fenomena tersebut pada akhir penelitian akan dikembangkan suatu inovasi dalam perawatan bayi baru lahir yang dilakukan oleh ibu secara mandiri. Hasil yang diperoleh dari pendekatan kualitatif akan diperkuat dengan pendekatan kuantitatif.

Teknik pengumpulan data yang dilakukan adalah wawancara, studi dokumen, observasi dan studi literatur. Wawancara dilakukan terhadap ibu postpartum, keluarga dan petugas kesehatan. Studi dokumen dilakukan untuk melihat data ibu, dan observasi untuk melihat kemampuan ibu melakukan perawatan bayi baru lahir. Data yang dikumpulkan melalui teknik pengumpulan data akan di lihat kata kuncinya. Kemudian kata kunci ini dikumpulkan dan kemudian di buat kalimat. Kalimat-kalimat yang mempunyai makna yang sama dikumpulkan. Kemudian hasil pengelompokkan ini di buat tema. Tema yang telah ada dikelompokan lagi berdasarkan kesamaan ini untuk kemudian di kategorikan. Dari kategori yang ada difokuskan pada kategori yang akan dirumuskan menjadi teori atau suatu pendekatan. Dari pendekatan yang dikumpulkan ini maka akan muncul suatu inovasi model. Dalam penelitian ini yang diharapkan adalah inovasi model perawatan bayi baru lahir.

\section{HASIL DAN PEMBAHASAN}

Pengambilan data telah dilakukan selama 3 bulan yaitu pada Bulan Juli September 2011 di Ruang Kebidanan RSUP Dr M DJamil Padang. Pada pengambilan data awal dilakukan studi dokumentasi terhadap jumlah ibu yang melahirkan di Ruang Kebidanan RSUP Dr M DJamil Padang sebagai data sekunder. Kemudian diambil sampel sebanyak 10 orang ibu postpartum. Untuk mengambil data primer dilakukan dengan 2 metode pengambilan data yaitu dengan kuesioner untuk mendapatkan data kuantitatif dan wawancara untuk mendapatkan data kualitatif. Pengambilan data kuantitatif ditujukan kepada responden dalam hal ini ibu postpartum. Data kuantitatif lebih mengarah kepada karakteristik responden. Sedangkan pengambilan data kualitatif ditujukan kepada responden, keluarga respoden dan tenaga kesehatan yang ada di ruangan. Data kualitatif diambil untuk melihat pandangan responden dan keluarga serta tenaga kesehatan terhadap perawatan bayi baru lahir.

Tabel 1 Distribusi Frekuensi Karakteristik Responden

\begin{tabular}{|l|c|c|}
\hline & $\begin{array}{l}\text { Jumlah } \\
(\mathrm{n})\end{array}$ & $\begin{array}{l}\text { Persentase } \\
(\%)\end{array}$ \\
\hline Usia & & \\
\hline$<20$ tahun & 1 & 10 \\
\hline $20-35$ tahun & 7 & 70 \\
\hline$>35$ tahun & 2 & 20 \\
\hline Total & 10 & 100 \\
\hline Paritas & & \\
\hline Primipara & 4 & 40 \\
\hline Multipara & 6 & 60 \\
\hline Total & 10 & 100 \\
\hline Hari Rawat & & \\
\hline 1 hari & 0 & 0 \\
\hline 2-3 hari & 7 & 70 \\
\hline '>3 hari & 3 & 30 \\
\hline Total & 10 & 100 \\
\hline
\end{tabular}

Dari tabel di atas dapat dilihat bahwa sebagian besar responden berada pada rentang usia 20 - 35 tahun dengan jumlah 7 responden atau $70 \%$. Sedangkan lebih dari separoh responden berada pada paritas multipara dengan jumlah 6 responden atau $60 \%$. Selanjutnya, jumlah hari rawat ibu pada pengambilan data mayoritas berada pada rentang hari ke-2 sampai dengan hari ke-3 dengan jumlah 70 responden atau $70 \%$ dan masih ada ada responden yang sudah di rawat pada hari ke-8.

Berdasarkan hasil wawancara, sebagian besar respoden mengatakan bahwa mereka mengetahui cara perawatan 
bayi baru lahir sebanyak $70 \%$ dan masih ada $30 \%$ ibu yang tidak mengetahui perawatan apa yang harus diberikan kepada bayinya. Dari $70 \%$ respoden yang mengetahui cara perawatan bayi baru lahir, hampir semuanya di bantu oleh tenaga kesehatan. Wawancara dengan $\mathrm{Ny} \mathrm{A}$, tentang perawatan bayi baru lahir, beliau mengatakan "Menurut saya perawatan bayi baru lahir seperti memandikan, membedong dan memberikan ASI, akan tetapi saya tidak tahu pasti apakah yang telah saya lakukan sudah benar atau belum". Sedangkan Ny M mengatakan "Saya belum pengalaman melakukan perawatan bayi baru lahir karena saya pertama kali melahirkan, tetapi saya dibantu oleh perawat dalam melakukan perawatan bayi saya". Selain itu, Ny Ad juga mengatakan "saya tidak percaya diri dalam melakukan perawatan bayi saya karena saya tidak pernah melakukan hal ini sebelumnya".

Sedangkan menyusui merupakan perawatan bayi baru lahir yang sering dilakukan mandiri oleh ibu seperti yang dikatakan oleh Ny R "Jika bayi menangis langsung saya susui karena dia lapar". Hal yang sama juga dikatakan oleh $\mathrm{Ny} \mathrm{N}$ "saya akan segera menyusui bayi jika terlihat menangis". Akan tetapi, saat dilakukan wawancara lebih lanjut ternyata $\mathrm{Ny} \mathrm{R}$ dan Ny $\mathrm{N}$ tidak mengetahui bagaimana cara menyusui yang benar dan kapan saja bayi harus diberikan air susu. Sementara itu, Ny F mengatakan "bayi saya belum mau menyusui padahal ASI saya banyak, mungkin dia tidak lapar". Lain halnya dengan Ny Y, beliau mengatakan "putting susu saya lecet sehingga perih pada saat bayi menyusui'. Sedangkan Ny Rn mengatakan "saya masih lelah karena abis operasi sehingga belum menyusui bayi".

Pada saat wawancara, sebagian besar responden $(70 \%)$ telah melakukan perawatan kebersihan seperti memandikan bayi dan perawatan tali pusat kepada bayinya. Akan tetapi mereka melakukannya dengan bantuan tenaga kesehatan baik dari ruangan maupun mahasiswa kesehatan yang sedang praktek lapangan. Disamping itu, terlihat juga sekitar $40 \%$ ibu mengalami kesulitan saat membedong bayinya. Hasil wawancara dengan respoden, $\mathrm{Ny} R$ mengatakan "Saya belum punya pengalaman membedong bayi, ternyata tidak mudah yaa..". Ny A juga mengatakan "padahal ini adalah anak ke-2 saya akan tetapi tetap juga susah melakukannya". Sementara itu, Ny T terlihat belum terampil memandikan bayi padahal Ny T merupakan multipara. Pada saat ditanyakan, Ny T menjawab "sudah lama saya tidak pernah memandikan bayi dan sepertinya saya harus belajar lagi bagaimana caranya". Lain halnya dengan Ny En, beliau mengatakan "takut memandikan bayi karena takut nanti bayi bisa jatuh".

Hasil wawancara dengan keluarga responden yang berjumlah 10 orang didapatkan data bahwa $100 \%$ anggota keluarga yang diwawancarai adalah suami. Semua suami mengatakan bahwa sangat penting bagi istri untuk mengetahui cara perawatan bayi baru lahir yang baik dan benar. 90\% suami setuju kalau istri melakukan perawatan bayi baru lahir secara mandiri. Hanya $10 \%$ suami yang mengatakan bahwa dia akan membantu istri melakukan perawatan bayi baru lahir. Suami Ny R mengatakan "perawatan bayi baru lahir seperti menyusui, memandikan, membedong bayi dan merawat tali pusat adalah hal penting yang harus dipelajari oleh istri saya". Pernyataan ini juga didukung oleh suami responden yang lainnya seperti suami $\mathrm{Ny} M$ yang mengatakan "sekarang ini adalah anak pertama kami, jadi perawatan yang terkait bayi seperti memandikan, merawat tali pusat, cara menyusui dan membedong sangat penting diketahui oleh istri saya agar dia bisa melakukannya sendiri secara mandiri".

Wawancara dengan tenaga kesehatan yang berjumlah 5 orang didapatkan data bahwa semua tenaga kesehatan (100\%) mengatakan program pendidikan kesehatan kepada ibu postpartum tentang perawatan bayi baru lahir sudah ada di ruangan. Adapun bentuk programnya adalah 
pendidikan kesehatan berupa penyuluhan, demonstrasi, belajar mandiri dan melakukan evaluasi. Salah satu responden yaitu tenaga kesehatan $\mathrm{Nn} \mathrm{D}$ mengatakan "kami sudah memberikan pendidikan kesehatan kepada ibu tentang cara menyusui, memandikan bayi dan perawatan tali pusat dan kegiatan ini kami berikan biasanya dalam bentuk penyuluhan kesehatan". Sementara itu, tenaga kesehatan lainnya yaitu $\mathrm{Nn} N$ mengatakan "Pendidikan kesehatan yang diberikan kepada ibu kadang-kadang berdasarkan kebutuhan akan tetapi kadang-kadang tidak". Dari 5 orang tenaga kesehatan, hanya 1 orang yang memberikan pendidikan kesehatan kepada ibu tentang perawatan bayi di rumah.

Berdasarkan hasil pengumpulan data baik secara kuantitatif dan kualitatif maka perumusan inovasi model tentang kemandirian ibu postpartum dalam melakukan perawatan bayi baru lahir dapat dirumuskan. Kata kunci yang pertama adalah perawatan bayi baru lahir, mandiri, ibu postpartum. Sedangkan kata kunci yang kedua adalah penyuluhan, demonstrasi, evaluasi dan mandiri. Kata kunci yang ketiga adalah laktasi, memandikan bayi, perawatan tali pusat, membedong bayi. Kata kunci yang keempat adalah perawatan bayi di rumah sakit, perawatan bayi di rumah. Dari semua kata kunci ini, kemudian digabungkan dan dibuat kalimat. Adapaun kalimat pertama yang merupakan gabungan dari kata kunci satu dan dua adalah Perawatan bayi baru lahir dapat dilakukan secara mandiri oleh ibu postpartum setelah dilakukan penyuluhan, demostrasi dan evaluasi. Sedangkan kalimat yang kedua merupakan gabungan dari kata kunci yang ketiga dan keempat yaitu perawatan bayi baru lahir dapat dilakukan dirumah sakit dan di rumah seperti manajemen laktasi, memandikan bayi, membedong bayi dan perawatan tali pusat. Kedua kalimat ini digabungkan dan dijadikan satu tema yaitu perawatan bayi baru lahir oleh ibu postpartum tentang manajemen laktasi, perawatan tali pusat, memandikan bayi dan membedong bayi baik dilakukan di rumah sakit maupun di rumah setelah pulang. Dari tema ini bisa dilakukan satu pendekatan untuk mencapai tujuan. Pendekatan yang bisa dilakukan adalah pendekatan dengan cara memandirikan ibu dalam perawatan bayi baru lahir atau dikenal dengan mother baby care.

Apalagi menurut Tomey (2002), pendekatan mother baby care merupakan suatu pendekatan yang bisa digunakan oleh ibu postpartum dalam merawat bayi secara mandiri. Ibu merupakan orang yang paling diharapkan untuk melakukan perawatan bayi secara langsung karena bayi merasa nyaman berada di dekat ibunya dan bayi akan belajar mengenal ibunya secara langsung sehingga timbul rasa saling percaya antara ibu dan bayi. Disamping itu, kepercayaan diri ibu dalam melakukan perawatan bayi akan muncul dan meningkat. Ibu akan merasa bangga terhadap dirinya sendiri.

Hasil penelitian ini juga sesuai dengan pendapat Pillittery (1999) yang mengatakan bahwa memandikan bayi, merawat tali pusat, membedong bayi dan memberikan ASI merupakan perawatan bayi baru lahir yang sebaiknya dilakukan oleh ibu. Perawatan ini sebaiknya dilakukan secara mandiri oleh ibu. Oleh karena itu, jika ibu tidak memiliki pengetahuan terkait maka ibu akan mengalami kesulitan dalam melakukan perawatan bayi baru lahir. Hasil penelitian juga memperlihatkan bahwa ibu masih butuh bantuan orang lain seperti tenaga kesehatan dalam melakukan perawatan bayinya. Hal ini lebih disebabkan karena adanya ketakutan ibu akan ketidakmampuannya melakukan perawatan bayi baru lahir disamping ketidaktahuannya bagaimana cara perawatan bayi baru lahir. Padahal banyak keuntungan yang didapat oleh ibu maupun bayi pada saat ibu mandiri melakukan perawatan bayi baru lahir seperti kembalinya organ-organ reproduksi ibu secara cepat seperti semula seperti sebelum hamil disamping terciptanya ikatan 
emosional yang kuat antara ibu dan bayi. Jika organ-organ reproduksi ibu lambat kembali seperti sebelum hamil bisa membahayakan bagi ibu dan bahkan bisa menimbulkan kematian ibu. Jika ini terjadi maka angka kematian ibu di Indonesia dan khususnya di Sumatera Barat tidak akan turun.

Pendekatan mother-baby care yang telah disepakati untuk memandirikan ibu dalam perawatan bayi baru lahir akan dibuat modulnya agar jelas langkah-langkah yang dilakukan oleh ibu saat melakukan perawatan bayi baru lahir. Modul yang akan di buat berupa modul manajemen laktasi, modul memandikan bayi, modul perawatan tali pusat dan modul membedong bayi. Modul ini akan dibuat pada penelitian selanjutnya dan akan langsung diujicobakan untuk melihat keefektifannya.

\section{KESIMPULAN DAN SARAN}

Model Mother-Baby Care (M-BC) merupakan suatu model inovasi dalam perawatan bayi baru lahir. Model ini sangat berguna bagi ibu postpartum baik dengan status primipara maupun multipara dalam melakukan perawatan bayi baru lahir secara mandiri. Disarankan kepada petugas kesehatan untuk dapat mengunakan model ini sebagai salah satu upaya dalam melakukan intervensi yang bertujuan untuk memandirikan ibu dalam melakukan perawatan bayi baru lahir. Sedangakan bagi ibu, model ini berguna sebagai pedoman ibu dalam melakukan perawatan bayi baru lahir sehingga ibu merasa lebih percaya diri sehingga mandiri dalam perawatan bayi. Begitu pula bagi keluarga dimana keluarga dapat mendampingi ibu pada saat ibu melakukan perawatan bayi baru lahir. Sedangkan bagi institusi pendidikan kesehatan, model ini bisa digunakan untuk menambah pengetahuan dalam perawatan bayi baru lahir.

\section{DAFTAR PUSTAKA}

Alligood \& Mariner Tomey.(2002). Nursing Theory: Utilization and Application. St Louis: Mosby

Bick, D; Macathur. C; Knowles. H. \& Winter, H. (2003). Postnatal care: Evidence and guidelines for management. Cina: Livingstone.

Burn, N. \& Grove, S.K. (2001). The practice of nursing research. $\left(4^{\text {nd }}\right.$ ed). Philadelphia: WB. Saunders Company.

Depkes .(2011). Pertolongan persalinan oleh tenaga kesehatan efektif turunkan AKI di Indonesia. Diakses melalui

http://www.depkes.go.id/index.php/ component/content/article/43newsslider/1076-pertolonganpersalinan-oleh-tenaga-kesehatanefektif-turunkan-aki-diindonesia.html. Diakses tanggal 9 April 2011.

May, K A \& Mahlmeister, L.R. (1994). Maternal and neonatal nursing family centered care. Philadhelpia: JB Lippincott Company

Pilliteri, A. (1999). Maternal and Childhealt Nursing care of the childbearing family. Philadelphia: William and Wilkins

Reeder. (1997). Maternity Nursing: Famili newborn and women's health care. Philadelphia: Lippincott

Streubert, J.H \& Carpenter, D.R. (1998). Qualitative Research in Nursing: Advancing the humanistic imperative. Philadelphia: Lippincott 